\title{
LABOR SUPPLY AND GROWTH EFFECTS OF ENVIRONMENTAL POLICY UNDER TECHNOLOGICAL RISK
}

\author{
Christiane Clemens \\ University of Bielefeld
}

Karen Pittel

Ifo Institute

and

University of Munich

This paper analyzes the effects of technological risk on long-run growth when labor supply is elastic and production gives rise to a pollution externality. We show that the randomness of production, as well as the endogeneity of labor supply, affects the equilibrium solutions for the social planner and for the market economy. We analyze the effects of environmental policy, discuss conditions for an optimal policy, and find that the response of labor supply to changes in the model parameters and to variations in the policy instruments crucially depends on the volatility of output.

Keywords: Stochastic Growth, Pollution, Abatement, Elastic Labor Supply

\section{INTRODUCTION}

When the fast growing body of literature dealing with economic growth and environmental externalities is reviewed, one feature is common to most contributions: economic outcomes are assumed to be deterministic. Although most economists would agree that this assumption is not very realistic, it has been dominating not only the environmental growth literature, but growth literature in general. Usually, the seeming contradiction between theory and reality has been justified by arguing that uncertainty may cause short-term economic fluctuations, but mean growth remains unaffected in the long run. Yet risk can affect long-run growth via various channels, e.g., by inducing precautionary savings or influencing the optimal labor-leisure choice. By integrating uncertainty in the form of aggregate technology shocks into an endogenous model with pollution, we show in this paper

The authors would like to thank two anonymous referees for helpful comments and suggestions. Address correspondence to: Karen Pittel, Ifo Institute for Economic Research and University of Munich, Poschingerstr. 5, 81679 Munich, Germany; e-mail: pittel@ifo.de. 
that uncertainty matters for the long-run development of the economy as well as for the implications of environmental policy.

To exemplify the relevance of our analysis, consider the consequences of climate change for the frequency of extreme weather events. The IPCC (2007), as well as Stern (2006), predicts that the volatility of temperatures and precipitation, and extreme weather events, will rise due to climate change. Environmental shocks such as storms, however, constitute one important source of aggregate technology shocks. Because the extent of climate change depends on the level of $\mathrm{CO}_{2}$ generating production, the volatility of output increases in a growing economy. To show the implications of such an increase for the growth path of an economy as well as the implications of environmental policy, in this paper we consider aggregate multiplicative technology shocks.

We argue that the consideration of uncertainty is of particular significance in the presence of environmental externalities. Concentrating on aggregate technological shocks as the source of uncertainty, we show that uncertainty affects the optimal static as well as the dynamic characteristics of optimal policy, not only quantitatively but also qualitatively. For example, in a deterministic setting, internalization of the pollution externality unambiguously increases labor supply. Yet this may not hold, given technological risk. Whether employment increases or decreases due to internalization depends crucially on the volatility of production: the higher the volatility, the more likely labor supply is to decrease with the degree of internalization. Consequently, a policy maker who strives to increase employment by raising environmental taxes could accomplish the opposite if he neglected the impact of technological risk.

We also show that the volatility of shocks matters with respect to vulnerability to pollution. In the absence of risk, a higher pollution elasticity of production, i.e., a higher vulnerability, is always harmful to optimal employment and growth. Consequently, a developing country whose economy depends more on environmentally sensitive sectors suffers more from pollution than, e.g., an industrialized economy. Yet, if risk is included in the analysis, a higher pollution elasticity might decrease growth less than in a deterministic setting, whereas employment could even be higher.

Our model is a stochastic version of the Romer (1986) endogenous growth model with endogenous labor supply and a negative pollution externality. Pollution is generated from production activities and can be reduced by devoting part of output to abatement. Production and abatement are subject to a random disturbance that stems from an aggregate productivity shock. The economy follows a stochastic trend with the assumed uncertainty leading to second-order effects on expected labor supply and growth. The relatively simple model structure with constant private returns to scale and linearity in capital allows us to derive closed-form solutions. In contrast to the main body of literature in this field, we assume labor supply to be endogenously determined. We show that neglecting the reaction of the labor-leisure choice to changes in environmental policy may result in a wrong assessment of policy implications. ${ }^{1}$ 
The mutual interdependence of economic growth and the environment has been addressed extensively in the recent literature. It has especially been the development of endogenous growth theory that has renewed interest in this field, leading to a broad analysis not only of long-run growth under environmental restrictions, but also of different types of environmental policies [e.g., Gradus and Smulders (1993); Grimaud (1999); Schou (2000, 2002); Grimaud and Rougé (2005); Groth and Schou (2007) ]. ${ }^{2}$ The vast majority of this literature, however, does not consider the effects of uncertainty, but rather assumes that economic as well as ecological components are deterministic. There are some exceptions, however. Baranzini and Bourguignon (1995), for instance, consider a nonzero probability of extinction, whereas Beltratti et al. (1998) and, more recently, Ayong Le Kama and Schubert (2004) include uncertainty about future preferences. Optimal timing of environmental policies under ecological as well as economic uncertainty is considered by Pindyck (2002). Ecological uncertainty thus refers to uncertainty with respect to ecosystem development, whereas economic uncertainty relates to uncertainty about future costs and benefits of environmental damages.

Technically closest to our analysis is probably Soretz (2003, 2004, 2007), who discusses perception and policy issues of environmental pollution in an $A K$-type framework, but disregards trade-off effects between consumption and leisure, as well as how individual households' savings decisions relate to a differentiated factor income risk.

In this paper, we combine the traditional environmental economics literature on growth and the environment with the strand of literature dealing with labor supply in a stochastic setting. The analysis is motivated by the well-known result from the literature that the riskiness of capital returns and labor income is an important determinant of the intertemporal savings decision of risk averse agents. In his pioneering work, Leland (1968) stressed the role of precautionary savings that a risk-averse household additionally undertakes in order to self-insure against the riskiness of future income flows. In the context of modern growth theory, this draws a link between intertemporal choice, risk, and growth. Sandmo (1970) was the first to point out the importance of factor-specific risk related to the degree of risk aversion for the emergence of precautionary saving.

The majority of recent contributions dealing with continuous-time stochastic growth, where the economy follows a stochastic trend, confine their analysis to a single income type (mostly capital risk), in order to maintain analytical tractability [cf. Turnovsky (1993); Obstfeld (1994); Smith (1996)]. Others either view the intertemporal flow of labor income as human wealth and treat it as a "quasi-accumulating" hedgeable asset [Corsetti (1997)], or assume labor incomes to be instantaneously deterministic [Turnovsky (2000, 2003)]. Notable exceptions for the case of inelastic labor supply are Clemens and Soretz (2004) and Clemens (2004, 2005). Recently, Turnovsky and Smith (2006) and Clemens (2009) succeeded in deriving closed-form solutions for the equilibrium growth path of an economy with endogenous labor-leisure choice, where households are simultaneously subject to capital and income risk. 
Besides the phenomenon of precautionary savings, the presence of risk substantially alters the policy implications derived for a deterministic environment. This is due to the fact that taxes (or transfers, respectively) also affect the riskiness of the policy target under consideration. The insurance effect of taxation in a nonenvironmental setting was first discussed by Domar and Musgrave (1944) and Stiglitz (1969), or in a continuous-time growth context by Turnovsky (1993), Smith (1996), or Clemens and Soretz (1997).

The paper proceeds as follows: Section 2 introduces the model. In Section 3, we determine the socially optimal growth path as a benchmark solution. Section 4 focuses on the market economy. We derive conditions for an optimal policy mix and discuss the general implications of regulatory activities on growth and labor supply. Section 5 concludes. Technical details are relegated to the Appendix.

\section{THE MODEL}

We assume a closed economy in which a homogeneous good is produced from labor and capital. We consider a large number of identical firms. Individual production is stochastic; i.e., with each increment of time, the economy is subject to an aggregate productivity shock. The production and investment processes generate two types of externalities: First, we assume that production is subject to learning by doing. Production of a single producer is positively affected by aggregate production experience, and investment activities in privately owned capital create a positive externality by raising the productivity of all firms. For simplicity it is assumed that this positive spillover effect is represented one to one by the aggregate level of capital input. This is the standard type of Romer (1986) model. A second externality arises from aggregate environmental pollution, $\bar{P}(t) .{ }^{3}$ Production leads to a flow of pollution, generating a negative effect on production, which can be mitigated by abatement activities. The production technology is assumed to be of the stochastic Cobb-Douglas type,

$$
\mathrm{d} Y(t)=K(t)^{\alpha} \bar{K}^{1-\alpha}[1-l(t)]^{1-\alpha} \bar{P}(t)^{-\eta}[\mathrm{d} t+\mathrm{d} z(t)], \quad \alpha \in(0,1), \eta \in(0,1) .
$$

$\mathrm{d} z(t)$ is the serially uncorrelated increment to a standard Wiener process $z(t)$ with zero mean and an instantaneous variance of $\sigma^{2} \mathrm{~d} t$. Due to the productivity shock, the returns to the two factors of production are stochastic. In the terms of Sandmo (1970), the household is subject to a capital risk and an income risk.

To generate the instantaneous output flow $\mathrm{d} Y(t)$, producers employ physical capital, $K(t)$, and labor, $1-l(t)$, as a fraction of time endowment. The production displays constant returns to scale in $K(t)$ and $1-l(t)$ on the individual firm level. Aggregate capital accumulation, $\bar{K}(t)$, exerts a positive effect on productivity. We normalize the population to unity, such that $K(t)$ equals $\bar{K}(t)$. Production is linear 
in capital on the aggregate level, which ensures that the conditions for ongoing growth of per capita incomes are met. This, together with the assumption that the productivity shock is proportional to the mean rate of output, implies that the randomness of production does not disappear asymptotically as output grows. The economy evolves according to a stochastic trend.

The negative pollution externality is represented by $P(t)$, with the impact weight on aggregate output measured by the partial elasticity $-\eta$. Pollution is generated by production activities and can be reduced by devoting a share of output to abatement. For simplicity we assume a one-to-one relationship between the nonenvironmental part of production and unabated pollution. The effective flow of pollution is given by the ratio of mean output to abatement $A$ :

$$
P(t)=\frac{K(t)^{\alpha} \bar{K}(t)^{1-\alpha}[1-l(t)]^{1-\alpha}}{A(t)} .
$$

The form of pollution addressed in our paper encompasses all types of flow pollution (e.g., noise) but may also serve as an approximation for pollution that is assimilated or decomposed in a short amount of time (e.g., air pollution). ${ }^{4}$

Following Smulders and Gradus (1996), we assume an elasticity of substitution of unity between abatement and raw pollution as a prerequisite for balanced growth to be consistent with nonincreasing effective pollution in the long run. As we assume perfect competition with a large number of producers, the effect of individual production on aggregate pollution is negligible, so that, on the individual level, producers take pollution as exogenous to their production decision. Consequently, producers would not - in the absence of environmental regulationconduct abatement, as their perceived marginal return would be zero, and effective pollution would asymptotically grow to infinity. Along the equilibrium growth path, aggregate pollution, $\bar{P}$, should be constant.

The economy is populated by a continuum $[0,1]$ of identical infinitely lived individuals who maximize their intertemporal utility out of consumption and leisure,

$$
\mathrm{E}_{0} \int_{0}^{\infty}\left[\ln C(t)+\frac{l(t)^{1-\delta}}{1-\delta}\right] e^{-\beta t} \mathrm{~d} t, \quad \text { if } \quad \delta>0, \delta \neq 1,
$$

and $\mathrm{E}_{0} \int_{0}^{\infty}[\ln C(t)+\ln l(t)] e^{-\beta t} \mathrm{~d} t$, if $\delta=1 . l(t)$ denotes leisure time, with $\delta$ measuring the household's dislike of labor. $C(t)$ is individual consumption and $\beta$ the intertemporal rate of time preference.

This intertemporal utility function has a number of important characteristics: First, (3) is log-linear in consumption. Households are risk averse and the ArrowPratt measure of relative risk aversion equals unity. From the literature on precautionary savings under uncertainty [cf. Levhari and Srinivasan (1969); Sandmo (1970)], it is well known for this case that the intertemporal income and substitution effects from changes in the interest rate and hence from capital risk completely offset each other. In a model without a preference for leisure, the randomness of production would then generate certainty-equivalence results regarding the 
allocation of personal income on consumption and saving. The equilibrium expected growth rate of this economy would be identical to the growth rate of a deterministic economy, although the household would still suffer a welfare loss due to the presence of uncertainty. Because our model also takes risky labor incomes into account, the chosen specification allows us to focus entirely on the growth and policy effects of labor income risk. As will become obvious below, the riskiness of wage incomes affects the labor-leisure choice and influences optimal pollution as well as optimal pollution taxation.

Second, by assuming the preferences of agents to be additively separable, the cross derivatives vanish and the effects of leisure on the marginal utility of consumption and vice versa are eliminated. Finally, (3) is consistent with a balanced growth path, along which the time share devoted to leisure as well as the return to capital is constant, whereas consumption grows at a constant rate [cf. King and Rebelo (1999)].

The aggregate capital stock follows the Itô diffusion process,

$$
\mathrm{d} \bar{K}(t)=\mathrm{d} \bar{Y}(t)-\bar{C}(t) \mathrm{d} t-\bar{A}(t)\left[\mathrm{d} t+\mathrm{d} z_{A}(t)\right],
$$

where $\bar{A}(t)$ denotes aggregate abatement expenditure, which also follows a stochastic process $\mathrm{d} z_{A}(t)$ to be endogenously determined at equilibrium.

We now proceed with the derivation of the Pareto-optimal growth path of the economy, which serves as a benchmark solution. The subsequent sections then are devoted to the analysis of an economic and environmental policy aiming at mimicking the Pareto-optimal path. It will be shown that the Pareto-efficient allocation can be implemented by means of a subsidy on physical capital and a pollution tax giving rise to incentives to engage in abatement, combined with lump-sum payments. Two instruments will be sufficient to induce the efficient time path in a knife-edge scenario.

\section{SOCIAL PLANNER}

\subsection{Optimization and Balanced Growth Path}

The benevolent social planner internalizes the two externalities present in the economy and also takes account of the fact that the diffusion process of abatement is governed by the exogenous productivity shock, such that $\mathrm{d} z_{A}(t)=\mathrm{d} z(t)$. In contrast to individual producers, who only take account of the private returns to capital, the social planner considers the social return and chooses the intertemporal consumption path, the working time, and the abatement efforts so that the spillover effects are internalized, and capital is paid its social return. In contrast to the standard Romer (1986) model, where the private return unambiguously falls short of the social returns to investment, this is not necessarily the case in our setting, the results depending on whether the positive learning spillovers are outweighed by the negative effects from pollution. 
The maximization problem of the social planner reads ${ }^{5}$

$$
\begin{array}{ll}
\max _{C, l} & \mathrm{E}_{0} \int_{0}^{\infty}\left[\ln C+\frac{l^{1-\delta}}{1-\delta}\right] e^{-\beta t} \mathrm{~d} t, \\
\text { s.t. } & \mathrm{d} K=\mathrm{d} Y-C \mathrm{~d} t-A(\mathrm{~d} t+\mathrm{d} z), \quad K(0)>0, z(0)=0 .
\end{array}
$$

The stochastic Hamiltonian can be set up as follows Malliaris and Brock (1982, Ch. 2.10): ${ }^{6}$

$$
\begin{aligned}
& H\left(C, K, A, l, \lambda, \frac{\partial \lambda}{\partial K}\right)=e^{-\beta t}\left(\ln C+\frac{l^{1-\delta}}{1-\delta}\right) \\
& +\lambda\left\{\left[K(1-l)^{(1-\alpha)}\right]^{(1-\eta)} A^{\eta}-C-A\right\}+\frac{\sigma_{K}^{2}}{2} \frac{\partial \lambda}{\partial K}
\end{aligned}
$$

with $\sigma_{K}^{2}=\left\{\left[K(1-l)^{(1-\alpha)}\right]^{(1-\eta)} A^{\eta}-A\right\}^{2} \sigma^{2}$. Maximization yields the following FOCs:

$$
\begin{aligned}
\frac{\partial H}{\partial C} & =e^{-\beta t} C^{-1}-\lambda=0 \\
\frac{\partial H}{\partial l}= & e^{-\beta t} l^{-\delta}-\lambda(1-\eta)(1-\alpha) K(1-l)^{-\alpha} a^{\eta} \\
\times & {\left[1+\frac{\partial \lambda}{\partial K} \frac{K}{\lambda}(1-l)^{1-\alpha} \sigma^{2}\left(a^{\eta}-a\right)\right]=0 } \\
\frac{\partial H}{\partial A} & =\left(\eta a^{\eta-1}-1\right) \lambda\left[1+\frac{\partial \lambda}{\partial K} \frac{K}{\lambda}(1-l)^{1-\alpha} \sigma^{2}\left(a^{\eta}-a\right)\right]=0 \\
\mathrm{~d} \lambda= & -\frac{\partial H}{\partial K} \mathrm{~d} t+\frac{\partial \lambda}{\partial K} \sigma_{K} \mathrm{~d} z \\
= & -\lambda\left\{(1-\eta)(1-l)^{1-\alpha} a^{\eta}\left[1+\frac{\partial \lambda}{\partial K} \frac{K}{\lambda}(1-l)^{1-\alpha}\left(a^{\eta}-a\right) \sigma^{2}\right] \mathrm{d} t\right. \\
- & \left.\frac{\partial \lambda}{\partial K} \frac{K}{\lambda}(1-l)^{1-\alpha}\left(a^{\eta}-a\right) \mathrm{d} z\right\},
\end{aligned}
$$

where $a=1 / \bar{P}$ denotes the abatement ratio, together with the transversality condition

$$
\lim _{t \rightarrow \infty} \mathrm{E}_{t}[\lambda(t) K(t)]=0
$$

Conditions (7) and (8) relate the marginal utility of consumption and leisure, respectively, to the shadow price $\lambda$, but (8) also accounts for the random nature of labor productivity. The optimal level of abatement activities follows from condition (9). Equation (10) is a modified version of the optimality condition usually derived 
for the state variable $K$. It describes the stochastic evolution of the shadow price over time, which also follows a diffusion process.

The term $\left(a^{\eta}-a\right)(1-l)^{1-\alpha} K$ in (8)-(10) will turn out to be crucial for the following analysis. It represents the part of output that is available for consumption and investment after abatement has been conducted to keep pollution and its negative productivity effects at bay, and can therefore be considered as "net" output. The term is also equal to $\sigma_{K} / \sigma$, and due to its linearity in the capital stock, it reflects the economy evolving according to a stochastic trend with $\sigma_{K}$ growing over time.

The solution procedure for the stochastic system (7)-(10) is similar to the wellknown one for deterministic models. We proceed with differentiating (7) with respect to time to obtain a second expression for the law of motion of the shadow price $\lambda$, which can then be equated to (10). Application of Itô's lemma yields the following expression for $\mathrm{d} \lambda$ :

$$
\mathrm{d} \lambda=e^{-\beta t} C^{-1}\left[-\beta \mathrm{d} t-\frac{\mathrm{d} C}{C}+\frac{(\mathrm{d} C)^{2}}{C^{2}}\right]
$$

With aggregate output being subject to a technological disturbance, consumption and saving are stochastic too. The associated diffusion process for consumption, $\mathrm{d} C$, can be obtained by applying Itô's lemma:

$$
\mathrm{d} C=C^{\prime}(K) \mathrm{d} K+\frac{1}{2} C^{\prime \prime}(K)(\mathrm{d} K)^{2} .
$$

A balanced growth path of the economy is characterized by a time-invariant expected growth rate. For this reason, the consumption-wealth ratio, $\mu=C / K$ and the abatement ratio, $a$, as well as the time fractions allotted to labor and leisure, $l$ and $1-l$, have to be constant over time, too. The solution conjecture of a time-invariant $\mu$ is consistent with the underlying isoelastic preferences [Eaton (1981); Merton (1982)]. We postulate $C^{\prime}(K)=\mu, C^{\prime \prime}(K)=0, \mathrm{~d} C=\mu \mathrm{d} K$, and $(\mathrm{d} C)^{2}=\mu^{2}(\mathrm{~d} K)^{2}$. Using the Itô multiplication rules ${ }^{7}$ finally yields

$$
\begin{aligned}
& \frac{\mathrm{d} \lambda}{\lambda}=\left\{-\beta+\mu-(1-l)^{1-\alpha}\left(a^{\eta}-a\right)\left[1-\sigma^{2}(1-l)^{1-\alpha}\left(a^{\eta}-a\right)\right]\right\} \mathrm{d} t \\
& \quad-(1-l)^{1-\alpha}\left(a^{\eta}-a\right) \mathrm{d} z .
\end{aligned}
$$

Equating (10) to (14) and sorting with respect to deterministic and stochastic components results in

$$
\begin{aligned}
& \left\{-\beta+\mu+a(1-l)^{1-\alpha}\left(1-\eta a^{\eta-1}\right)+\sigma^{2}(1-l)^{2(1-\alpha)}\left(a^{\eta}-a\right)\right. \\
& \left.\quad \times\left[a^{\eta}-a+(1-\eta) a^{\eta} \frac{\partial \lambda}{\partial K} \frac{K}{\lambda}\right]\right\} \mathrm{d} t=-a^{\eta}(1-l)^{1-\alpha}\left(\frac{\partial \lambda}{\partial K} \frac{K}{\lambda}+1\right) \mathrm{d} z .
\end{aligned}
$$


For $\mu$ to be nonstochastic over time, the random components on the RHS of (15) have to exactly offset each other, which is only the case if the elasticity of the shadow price with respect to capital equals the elasticity of marginal utility with respect to consumption, the latter being equal to unity in the case of log-utility:

$$
-\frac{\partial \lambda}{\partial K} \frac{K}{\lambda}=1
$$

Employing this condition and rearranging finally gives the following expression for the consumption-capital ratio, reflecting the consumption-saving trade-off: ${ }^{8}$

$$
\mu_{1}^{*}=\beta+a(1-l)^{1-\alpha}\left(\eta a^{\eta-1}-1\right)\left[1-\sigma^{2}(1-l)^{1-\alpha}\left(a^{\eta}-a\right)\right] .
$$

Going back to the first-order condition related to the labor-leisure choice, (8), utilizing (16), and rearranging, we derive a second condition for $\mu$, this time reflecting the consumption-leisure trade-off

$$
\mu_{2}^{*}=\frac{(1-\alpha) l^{\delta}}{(1-l)^{\alpha}}(1-\eta) a^{\eta}\left[1-\sigma^{2}(1-l)^{1-\alpha}\left(a^{\eta}-a\right)\right]
$$

To have a feasible allocation characterized by a positive value of (18), and given $\eta<1$, the last term on the RHS has to be of positive sign. By (10), we find that this condition is only met if the certainty equivalent to capital return,

$$
r_{s}^{*}=(1-\eta) a^{\eta}(1-l)^{1-\alpha}\left[1-\sigma^{2}(1-l)^{1-\alpha}\left(a^{\eta}-a\right)\right],
$$

is positive. The certainty equivalent is the real interest rate of a (hypothetical) safe asset, which falls below the rental rate to capital $r=(1-\eta) a^{\eta}(1-l)^{1-\alpha}$ by the amount of the risk premium $\sigma^{2} a^{\eta}(1-\eta)(1-l)^{2(1-\alpha)}\left(a^{\eta}-a\right)$, because risk-averse households demand a higher expected return for bearing the risk of accumulation. ${ }^{9}$

Equations (16) and (19) can now be used to derive results regarding the optimal level of abatement activities in terms of an optimal abatement ratio. From (9) follows

PROPOSITION 1. Abatement is conducted optimally if the marginal damage generated by pollution equals the marginal costs of abatement: i.e., for an optimal abatement ratio,

$$
a^{*}=\eta^{\frac{1}{1-\eta}} .
$$

We find $\mathrm{d} a^{*} / \mathrm{d} \eta>0$ and $\mathrm{d}^{2} a^{*} / \mathrm{d} \eta^{2}<0$.

Proposition 1 states a condition that is well known from the nonstochastic model. The optimal abatement ratio $a^{*}$ is solely determined by the pollution elasticity of production. The more vulnerable output is with respect to pollution, the higher the abatement ratio, i.e., the higher the share of production which has to be spent on abatement activities. 
Using this information allows us to rewrite (17) and (18):

$$
\begin{aligned}
& \mu_{1}^{*}=\beta, \\
& \mu_{2}^{*}=l^{\delta} \frac{(1-\alpha)(1-\eta) \eta^{\frac{\eta}{1-\eta}}}{(1-l)^{\alpha}}\left[1-\sigma^{2}(1-l)^{1-\alpha}(1-\eta) \eta^{\frac{\eta}{1-\eta}}\right] .
\end{aligned}
$$

$\mu_{1}^{*}$ and $\mu_{2}^{*}$ are functions of the model primitives and the time allocation only. They have to be equal to be consistent with balanced growth, which also implies that the time share devoted to leisure has to be time-invariant, too. Because (22) is a nonlinear function in working time, the optimal time allocation is only implicitly determined by $\mu_{1}^{*}=\mu_{2}^{*}$.

Equation (21) also reflects the well-known certainty equivalent result, which is typical for logarithmic preferences. Because the social planner internalizes the external effects, capital accumulation is rewarded by the social return to capital, which amounts to a pure capital risk. ${ }^{10}$ The optimal consumption-capital ratio is solely determined by the rate of time preference, and the intertemporal income and substitution effects originating from the riskiness of the income source exactly offset each other. This also implies that the household's consumption-accumulation decision is independent of the pollution generated through production.

By equating (21) and (22), we get an expression implicitly describing the optimal allocation of time to labor and leisure in the Pareto-efficient economy:

$$
l^{-\delta}=\frac{(1-\alpha)(1-\eta) \eta^{\frac{\eta}{1-\eta}}}{\beta(1-l)^{\alpha}}\left[1-\sigma^{2}(1-l)^{1-\alpha}(1-\eta) \eta^{\frac{\eta}{1-\eta}}\right] .
$$

An equilibrium growth path is characterized by capital and consumption growing at a common stochastic rate, that is, $\mathrm{d} K / K=\mathrm{d} C / C$. The equilibrium expected growth rate can be derived by employing the aggregate resource constraint, (4), together with (21) and (22), and taking expectations. We obtain two expressions for the optimal expected growth rate, which-similarly to the consumption-capital ratios $\mu_{1}^{*}$ and $\mu_{2}^{*}$-implicitly determine the equilibrium allocation of labor:

$$
\begin{aligned}
& g_{1}^{*}=(1-\eta) \eta^{\frac{\eta}{1-\eta}}(1-l)^{1-\alpha}-\beta \\
& g_{2}^{*}=(1-\eta) \eta^{\frac{\eta}{1-\eta}}(1-l)^{1-\alpha}\left\{1-\frac{(1-\alpha) l^{\delta}}{1-l}\left[1-\sigma^{2}(1-\eta) \eta^{\frac{\eta}{1-\eta}}(1-l)^{1-\alpha}\right]\right\} .
\end{aligned}
$$

The expected growth rate (24) reflects the well-known result that per capita incomes in the economy are growing at a constant positive rate if the (social) return to capital exceeds the rate of time preference. There are no direct higher-order effects from the variance of the productivity shock and the associated capital risk on expected growth because the intertemporal income and substitution effects exactly offset each other. Indirectly, the expected growth rate depends on the variance of the technological disturbance via optimal labor supply. A closer inspection of 
(25) shows that here, too, a positive certainty equivalent is crucial for a feasible allocation.

The economy is in equilibrium if the two growth rates are equal, i.e., $g_{1}^{*}=g_{2}^{*}=$ $g^{*}$, or equivalently if

$$
\begin{aligned}
\Delta^{*} & \equiv g_{1}^{*}-g_{2}^{*}=-\beta+\frac{(1-\alpha)(1-\eta) \eta^{\frac{\eta}{1-\eta}} l^{\delta}}{(1-l)^{\alpha}} \\
& \times\left[1-\sigma^{2}(1-\eta) \eta^{\frac{\eta}{1-\eta}}(1-l)^{1-\alpha}\right]=0 .
\end{aligned}
$$

PROPOSITION 2. A unique balanced growth path exists if

(i) $r_{s}>0$,

(ii) $\Delta^{*}$ is a continuous and monotonic function in the domain $l \in(0,1)$, and

(iii) the limits of $\Delta^{*}$ are of opposite sign:

$$
\operatorname{sgn} \lim _{(1-l) \rightarrow 0} \Delta^{*}=-\operatorname{sgn} \lim _{(1-l) \rightarrow 1} \Delta^{*} .
$$

Proof. Differentiation of (26) with respect to $1-l$ gives

$$
\frac{\partial \Delta^{*}}{\partial(1-l)}=-(1-\alpha) l^{\delta}\left\{\frac{r_{s}}{1-l}\left(\frac{\delta}{l}+\frac{\alpha}{1-l}\right)+\alpha\left[\frac{(1-\eta) \eta^{\frac{\eta}{1-\eta}} \sigma}{(1-l)^{\alpha}}\right]^{2}\right\} \text {. }
$$

For $r_{s}>0, \Delta^{*}$ is monotonically decreasing in $1-l$. The limits of $\Delta^{*}$ with respect to $(1-l) \rightarrow 0$ and $(1-l) \rightarrow 1$ are given by

$$
\lim _{(1-l) \rightarrow 0} \Delta^{*}=\infty \quad \text { and } \quad \lim _{(1-l) \rightarrow 1} \Delta^{*}=-\beta
$$

The allocation is feasible for positive values of $\mu^{*}, g^{*}$, and $l^{*}$ and if the transversality condition (11) is satisfied, so that the utility integral (5) converges and the maximized value of expected lifetime utility after substitution of the equilibrium values of the macroeconomic variables is given by

$$
\begin{gathered}
V(0)=\frac{1}{\beta^{2}}\left\{\beta\left[\ln \mu^{*}+\ln K(0)\right]+\frac{\beta l^{* 1-\delta}}{1-\delta}+g^{*}\right. \\
\left.-\frac{1}{2}(1-\eta)^{2} \eta^{\frac{2 \eta}{1-\eta}}(1-l)^{2(1-\alpha)} \sigma^{2}\right\}>0 .
\end{gathered}
$$

If households have no preference for leisure, the entire time endowment is devoted to working, so that $l=0$. Equations (20) and (21) show immediately that the optimal abatement ratio $a^{*}$ and the optimal consumption-capital ratio $\mu^{*}$ are unaffected by the endogeneity of labor supply. The major difference between the 
two settings can be found in the expected growth rate of the economy. This takes on its certainty equivalent level $g^{*}(l=0)=(1-\eta) \eta^{\eta / 1-\eta}-\beta$.

Although the optimal share of output devoted to abatement activities remains unchanged, optimal expected growth is higher in the exogenous labor case due to the increase in labor input:

$$
g^{*}(l=0)-g^{*}=(1-\eta) \eta^{\frac{\eta}{1-\eta}}\left[1-(1-l)^{1-\alpha}\right]>0
$$

\subsection{Comparative-Static Results for the Pareto-Efficient Allocation}

Whereas the optimal consumption-capital ratio (21) is only determined by the rate of time preference, optimal growth and leisure also depend on the remaining model parameters. By employing the implicit function theorem, we can show how optimal labor input (23) and (indirectly) expected growth (24) respond to changes in the model parameters. We focus especially on $\eta$, which reflects the vulnerability of production with respect to pollution; $\sigma^{2}$, measuring the impact of changes in the riskiness of production; and finally $\delta$, representing the elasticity of marginal utility with respect to leisure.

PROPOSITION 3. Optimal labor supply and the expected growth rate of the economy respond to changes in the model primitives according to

(i)

$$
\begin{aligned}
& \frac{\mathrm{d}\left(1-l^{*}\right)}{\mathrm{d} \sigma^{2}}<0, \quad \frac{\mathrm{d}\left(1-l^{*}\right)}{\mathrm{d} \delta}<0, \quad \frac{\mathrm{d}\left(1-l^{*}\right)}{\mathrm{d} \eta} \lesseqgtr 0 \\
& \text { for } 1 \gtreqless 2 \sigma^{2}(1-l)^{1-\alpha}(1-\eta) \eta^{\frac{\eta}{1-\eta}} ;
\end{aligned}
$$

(ii)

$$
\frac{\mathrm{d} g^{*}}{\mathrm{~d} \sigma^{2}}<0, \quad \frac{\mathrm{d} g^{*}}{\mathrm{~d} \delta}<0, \quad \frac{\mathrm{d} g^{*}}{\mathrm{~d} \eta}<0
$$

Proof. See Appendix A.1.

Changes in $\eta$. Equation (29) shows that the growth effect of an increase in the pollution elasticity of output is unambiguously negative, whereas the response of optimal labor supply is of ambiguous sign. An increase in $\eta$ implies that the economy becomes more vulnerable with respect to pollution. Identical amounts of pollution cause higher damages in terms of foregone output, so that it is optimal for the social planner to increase optimal abatement [see (20)] in order to reduce pollution.

To explain the ambiguity of adjustments in labor supply following a change in $\eta$, first consider as a reference the riskless economy, that is, the case of $\sigma=0$. Here, we find an unambiguously negative impact of larger values of $\eta$ on labor 
supply and growth. A higher $\eta$ negatively affects the marginal products of input factors, making it optimal to substitute labor for more leisure. Both, the decline in working time and the increase in optimal abatement, reduce growth.

This causality chain - reflecting first-order effects from the mean-is generally maintained in the stochastic environment, but is additionally augmented by secondorder effects from the variance of the technology shock, which also affect marginal labor productivity and consequently labor supply. To understand these secondorder effects, note that the FOCs with respect to consumption and leisure, (7) and (8), can be equated and rearranged to relate the marginal rate of substitution to the risk-adjusted marginal product of labor, ${ }^{11}$

$$
\frac{U_{l}}{U_{C}}=Y_{l} \times\left[1-\sigma^{2}(1-l)^{1-\alpha}(1-\eta) \eta^{\frac{\eta}{1-\eta}}\right],
$$

which responds to changes in $\eta$. As can be seen, the ratio of marginal utilities is lower under risk if compared to the riskless economy. The second-order term related to the instantaneous variance of the productivity shock, $\sigma^{2}$, enters negatively into the expression on the RHS side of equation (31). It reflects the risk-averse household's response to the presence of stochastic capital and labor incomes and the associated consumption risk. Bearing in mind that leisure is a riskless activity, the household's decision is biased toward enjoying more leisure in a risky compared to a riskless environment.

The second-order term decreases with a rise in $\eta$, generally implying an increase in the expression on the RHS of (31). To maintain equality, the marginal rate of substitution has to adjust accordingly, meaning an increase of $U_{l}$ relative to $U_{C}$. Concavity implies that a decrease in $U_{C}$ is accompanied by more consumption, less leisure, and consequently an increase in labor supply.

Associated feedback effects on expected growth mitigate the overall decline in growth, but never outweigh the first-order effects stemming from mean returns. Consequently, a more pollution-sensitive economy always grows at a lower rate.

Changes in $\delta$. Other things equal, an increase in $\delta$ raises marginal utility of leisure; see (29). This induces the social planner to substitute leisure for labor. The negative growth effect of (30) derives directly from the decline in labor supply. There are no second-order effects associated with a change in $\delta$.

Changes in $\sigma^{2}$. Equation (29) shows that the socially optimal labor supply responds qualitatively similarly to an increase in the variance of the technology shock and to an increase in the utility parameter $\delta$. In the presence of logarithmic preferences with respect to consumption, an increase in $\sigma^{2}$ does not have an effect on the household's optimal propensity to consume. Nevertheless, second-order effects from the productivity shock on the labor-leisure trade-off can be observed. The increase in $\sigma^{2}$ lowers the RHS of (31) and affects the shadow price between 
consumption and leisure. Here, the effects already described for a change in $\eta$ are reversed.

The marginal rate of substitution, $U_{l} / U_{C}$, decreases only if the marginal utility from labor declines relative to the marginal utility of consumption. Given concavity of utility, this is only the case if leisure time increases. The risk-averse household responds to the increase in income risk and associated consumption risk by extending its demand for the safe activity, i.e., leisure.

The associated decrease in working time causes negative growth effects [see (30)], which follow directly from (24). It reduces net output (output minus abatement effort), while leaving $\mu^{*}$ unchanged at the cost of savings and growth.

\section{THE MARKET ECONOMY}

\subsection{Policy Instruments}

We now proceed with the discussion of the market economy. Households ultimately own firms. Because we initially assumed all individuals to be identical, we will confine our analysis to the representative consumer, who chooses his intertemporal consumption flow, working and leisure time, and abatement efforts to maximize his intertemporal welfare (3) subject to his budget constraint, while treating public policy as exogenously given.

We assume that the household is subject to environmental taxation. As a firm owner, it pays a pollution tax at the rate $\tau^{p}$, but disregards its individual contribution to the overall level of pollution as a byproduct of production activities. Because the firm-specific flow of pollution, $P(t)$, generated throughout the production process, is also subject to the aggregate technological disturbances, we postulate the following diffusion for individual tax payments:

$$
\mathrm{d} T^{p}(t)=\tau^{p} P(t)[\mathrm{d} t+\mathrm{d} z(t)] .
$$

We assume identical rates for the taxes levied on the deterministic and the random components of pollution. $^{12}$

The household receives a subsidy on capital accumulation. Subsidy payments are proportional to the level of physical capital at the rate $\tau^{k}$ and follow the diffusion

$$
\mathrm{d} T^{k}(t)=\tau^{k} K(t)[\mathrm{d} t+\mathrm{d} z(t)] .
$$

Net government revenues (may they be positive or negative) are redistributed to households in a lump-sum fashion.

The representative agent maximizes welfare (3) subject to his budget constraint,

$$
\mathrm{d} K(t)=\mathrm{d} Y(t)-C(t) \mathrm{d} t-A(t)(\mathrm{d} t+\mathrm{d} z)-\mathrm{d} T^{p}(t)+\mathrm{d} T^{k}(t)+\mathrm{d} T(t) .
$$

The government balances its budget in each period of time. There is no government debt or surplus, so the diffusion of lump-sum payments $T(t)$ follows 
residually from (32) and (33),

$$
\mathrm{d} T(t)=\mathrm{d} T^{p}(t)-\mathrm{d} T^{k}(t),
$$

and, depending on the expenditure and revenue flows, can be stochastic too.

In contrast to a riskless environment, taxation and subsidization both target equally mean economic activities and random fluctuations around the mean. Although the technology shock has zero mean, the variance of the capital stock increases over time. Neglecting the stochastic structure of production and abatement in the policy mix would leave polluting economic activities partly untaxed, and these effects would accumulate over time. As the social planner takes account of the technology risk in his allocation decisions, a fiscal policy solely targeted at mean economic activities would run short of its goal and would never be sufficient to fully internalize the external effects.

\subsection{Macroeconomic Equilibrium}

The solution procedure is similar to the one already outlined above. The details of optimization are given in Appendix A.2. We start the discussion of the macroeconomic equilibrium with the determination of factor prices. The equilibrium values of factor prices can be obtained by the usual marginal productivity conditions of the firm problem. Taking account of (1) and the fact that $\bar{K}=K$ and $\bar{P}=1 / a$ in equilibrium, the pretax values of the expected return to capital and the expected wage rate can be obtained as

$$
r=\alpha(1-l)^{1-\alpha} a^{\eta} \quad \text { and } \quad w=(1-\alpha)(1-l)^{-\alpha} a^{\eta} K
$$

The expected rate of return to physical capital is constant in macroeconomic equilibrium and differs from the expected social return $r^{*}=(1-\eta) \eta^{\eta /(1-\eta)}(1-$ $l)^{1-\alpha}$, because agents of the market economy disregard both their own contribution to the formation of the aggregate capital stock, which exerts a positive knowledge externality, and their impact on aggregate pollution and the associated negative externality. The expected wage rate grows linearly in the capital stock.

By also taking account of the policy instruments, we are able to derive the following expression for the post-tax certainty equivalent to capital return in the decentralized economy:

$$
r_{s}=\left[\alpha a^{\eta}(1-l)^{1-\alpha}+\tau^{k}-\frac{\alpha \tau^{p}}{a K}\right]\left[1-\sigma^{2}(1-l)^{1-\alpha}\left(a^{\eta}-a\right)\right] .
$$

The equilibrium riskless rate $r_{s}$ nicely demonstrates the multiple ways fiscal policies affect accumulation in a risky environment. The two policy instruments have a twofold impact on the riskless rate. Both affect the mean return as well as the risk premium on capital holdings, the latter capturing the second-order effects stemming from the variance of the technological disturbance. ${ }^{13}$ The first 
expression on the RHS equals net mean return to capital, which is positively affected by the subsidy and negatively by the pollution tax.

In the first place, we have the well-known result that a subsidy paid on capital accumulation makes savings more attractive by an increase in mean capital return. Second, a subsidy also increases the volatility of future capital income flows, which risk-averse agents dislike, and ultimately is reflected by an increase in the risk premium on capital holdings.

The sign of effects reverses when it comes to the pollution tax. Being tied to current production and putting a burden on capital accumulation, the pollution tax reduces the mean return as well the volatility of future real interest incomes. This leads to a lower risk premium on capital accumulation.

To have a positive value of the certainty equivalent to capital return, we need the first-order effects to prevail, so that the last term on the RHS of (37) is of positive sign. ${ }^{14}$

Following the solution procedure described for the social optimum in the preceding section, we also obtain two expressions for the equilibrium consumptioncapital ratio. By additionally taking into account that the government has to run a balanced budget, we arrive at

$$
\mu_{1}=\beta+\left\{\left[(1-\alpha) a^{\eta}-a\right](1-l)^{1-\alpha}-\tau^{k}+\frac{\alpha \tau^{p}}{a K}\right\}\left[1-\sigma^{2}(1-l)^{1-\alpha}\left(a^{\eta}-a\right)\right] .
$$

As before, the second expression for $\mu$ can be obtained from the first-order condition for leisure:

$$
\mu_{2}=\frac{(1-\alpha) l^{\delta}}{1-l}\left[a^{\eta}(1-l)^{1-\alpha}-\frac{\tau^{p}}{a K}\right]\left[1-\sigma^{2}(1-l)^{1-\alpha}\left(a^{\eta}-a\right)\right] .
$$

A comparison between the consumption-capital ratio chosen by the benevolent social planner $\mu_{1}^{*}=\beta$ and the one of the decentralized market economy, (38), illustrates the impact of factor income risk on intertemporal consumption choice. Whereas the social planner rewards capital with its social return-which equals the value of output-and therefore indirectly neglects labor income risk, labor and capital inputs of the market economy are paid according to private marginal productivity. The intertemporal income and substitution effects related to capital risk still offset each other, but we no longer observe the certainty equivalent result that the consumption-capital ratio is unaffected by risk (reflected in the secondorder terms). We find that $\mu_{1}$ increases with mean labor income, measured by the term $\left[(1-\alpha) a^{\eta}-a\right](1-l)^{1-\alpha}$, and decreases with labor income risk, measured by the second-order term $-(1-l)^{2(1-\alpha)}\left(a^{\eta}-a\right) \sigma^{2}\left[(1-\alpha) a^{\eta}-a\right]$.

As Leland (1968) pointed out, decreasing absolute risk aversion is necessary and sufficient for households to save out of precautionary motives in the presence of a pure income risk. This condition is met for any positive value of the coefficient of relative risk aversion, which in our model equals unity by the assumption of log 
utility in consumption. Furthermore, as demonstrated by Levhari and Srinivasan (1969) and by Sandmo (1970), households have to be sufficiently risk-averse in the presence of a pure capital risk to undertake buffer-stock savings, which for the underlying isoelastic preferences corresponds to all values of relative risk aversion larger than unity. There is no savings effect from the riskiness of capital incomes for log-utility in consumption. Consequently, if we observe any impact from risk on intertemporal consumption choice, this can be attributed entirely to the presence of labor income risk.

For any given policy mix not mimicking the Pareto-efficient allocation, the effects of labor income risk on consumption and saving prevail and we find $\mu_{1}$ to be smaller if compared to a riskless environment (i.e., $\sigma=0$ ). This indicates the presence of precautionary savings that the household undertakes in order to self-insure against the fluctuations of future income flows.

This also implies that the consumption-accumulation decision of the household now depends not only on the pollution elasticity of production and the other model parameters, but also on the tax and subsidy rates. The underlying tax-transfer system indirectly redistributes income between labor and capital. It subsidizes accumulation while simultaneously taxing pollution, which is created as a byproduct of private capital and labor inputs in production. From the first-order condition for abatement activities (see Appendix A.2), we are able to derive an expression for the optimal relation between $\tau^{p}$ and $a$,

$$
0=\left(\frac{\tau^{p}}{A}-a\right)\left[1-\sigma^{2}(1-l)^{1-\alpha}\left(a^{\eta}-a\right)\right],
$$

which is satisfied only for a positive value of $r_{s}$, if $\tau^{p}=a A$. From (40), it can be seen that a constant abatement ratio over time is only consistent with household optimization if tax payments increase over time. Due to the accumulation of capital, the marginal value of a unit of pollution rises over time. To keep pollution from growing over time, its costs in terms of the tax have to rise as well [see also Pittel (2002)]. At the same time, the tax on pollution serves as an implicit subsidy on abatement, which increases in a growing economy. Along any balanced path, the growth rate of the tax has to be equal to the joint growth rate of abatement and capital. From $\tau^{p}=a A$ it follows immediately that tax revenues exactly suffice to pay for abatement expenditures.

Equation (38) shows that a constant propensity to consume, which is a prerequisite for balanced growth, requires the subsidy rate on capital to be constant over time. However, although the rates of the two policy instruments develop differently over time, the growth rates of tax revenues and subsidy payments are of course identical. For $\tau^{k}$ the subsidy basis grows at the same rate as the pollution tax. Nevertheless, a balanced budget of the regulating authority without any lump-sum transfers, i.e., $T=0$, can only hold for an optimal policy in a knife-edge case, as will be shown below.

We conclude the discussion of the macroeconomic equilibrium with the corresponding expressions for the expected growth rate of the decentralized economy, 
which can be obtained from the resource constraint (34) for a balanced government budget and the two expressions for the propensity to consume, (38) and (39):

$$
\begin{aligned}
& g_{1}=(1-l)^{1-\alpha}\left(a^{\eta}-a\right)-\mu_{1}, \\
& g_{2}=(1-l)^{1-\alpha}\left(a^{\eta}-a\right)-\mu_{2} .
\end{aligned}
$$

The impact of risk, which negatively affects consumption, is of opposite sign in the expected growth rate of the economy (41), thereby indicating the presence of precautionary saving, which is empirically supported, e.g., by Zeldes (1989), Caballero (1990), and Hubbard et al. (1994).

The economy is in equilibrium if the two growth rates are equal, i.e., $g_{1}=g_{2}=$ $g$, which implicitly determines the equilibrium level of labor supply,

$$
\begin{aligned}
\Delta & \equiv g_{1}-g_{2}=-\beta+\left\{1-\sigma^{2}(1-l)^{1-\alpha}\left[\left(\tau_{A}^{p}\right)^{\eta}-\tau_{A}^{p}\right]\right\} \\
& \times\left\{(1-l)^{1-\alpha}(1-\alpha)\left[\left(\tau_{A}^{p}\right)^{\eta}-\tau_{A}^{p}\right]\left(\frac{l^{\delta}}{1-l}-1\right)+\tau^{k}\right\}=0,
\end{aligned}
$$

where we considered $\tau^{p}=a A$ from (40) and define $\tau_{A}^{p} \equiv \tau^{p} / A$ for notational convenience. $\tau_{A}^{p}$ can be considered as the tax per unit of abatement activities, i.e., a normalized tax that is constant over time. The associated conditions for existence and uniqueness of a macroeconomic equilibrium along the balanced growth path closely resemble those stated for the Pareto-efficient solution in Proposition 2 and therefore are relegated to Appendix A.3.

For the case of exogenous labor supply, it follows from (40) that the equilibrium abatement ratio is entirely determined by the chosen tax policy, that is, $a=\tau_{A}^{p}$, and therefore is unaffected by the labor-leisure choice. For this reason, we would observe identical (expected) pollution levels in the exogenous and endogenous labor setting and an identical first-best policy, expressed by the normalized tax $\tau_{A}^{p *}=\eta^{1 /(1-\eta)}$.

This is, however, true only for the normalized rate $\tau_{A}^{p}$. The nonnormalized tax payments, $\tau^{p}=\eta^{1 /(1-\eta)} A$, will differ between the two scenarios, because $A$ follows a different time path. Recalling that optimal growth is higher in the exogenous labor case, tax payments $\tau^{p}$, too, will grow at a larger rate in the case of inelastic labor supply.

The optimal capital subsidy, however, is larger for the case of inelastic labor supply, the difference between optimal rates being given by $(1-\alpha)(1-$ $\eta) \eta^{\eta /(1-\eta)}\left[1-(1-l)^{1-\alpha}\right]>0$. This result can be explained by taking account of the fact that cross partial derivatives are positive in production technology. The larger the labor inputs, the larger the productivity gain from the technological externality, and the larger the wedge between private and social return, which has to be closed by the subsidy. 


\subsection{The Optimal Policy}

By choosing a policy mix that completely internalizes the pollution and capital externalities, governmental regulation can induce socially optimal growth in the market economy. The respective optimal rates of the pollution tax and the capital subsidy can be shown to follow the same general rules as in a standard deterministic economy.

PROPOSITION 4. An optimal policy mix is characterized by a capital subsidy and a pollution tax whose rates are equalized to the respective marginal externalities of pollution and capital:

$$
\tau^{p *}=\eta a^{\eta} A \quad \text { and } \quad \tau^{k *}=(1-\eta)(1-\alpha) a^{\eta}(1-l)^{1-\alpha} .
$$

Proof. Insert $\tau_{A}^{p *}$ and $\tau^{k *}$ into (38) and (39) to retrieve the two expressions for the socially optimal propensity to consume, (21) and (22). Substitution of these expressions into (41) and (42) gives (24) and (25). Substituting (44) into (40) yields the familiar condition

$$
a\left(\eta a^{\eta-1}-1\right)\left[1-\sigma^{2}(1-l)^{1-\alpha}\left(a^{\eta}-a\right)\right]=0,
$$

which is identical to (9). Consequently we get for the above described policy $a=a^{*}$.

Following Proposition 4, the optimal capital subsidy rate is constant over time while the optimal pollution tax rises with $A$. The latter result is due to optimal pollution being constant and therefore getting more and more "scarce" over time. To keep pollution at its optimal level $P^{*}$, the tax $\tau^{p *}$ has to increase to induce firms to increase their abatement activities over time. Governmental expenditures and revenues develop at identical growth rates. On the one hand, the subsidy rate on capital is time-invariant, whereas its base grows at rate $g^{*}$. On the other hand, the pollution tax base is kept constant with a growing tax rate.

Regarding (44), it can be seen that the pollution externality affects the optimal level of the capital subsidy. In contrast to an economy without pollution, the learning-by-doing spillover in our economy has a twofold effect on production: The positive direct effect on the social return and an indirect negative effect from the repercussions of capital accumulation on pollution. The optimal subsidy rate in (44) corrects for the net of the two effects.

Regarding lump-sum transfers we find

COROLLARY 1. Lump-sum transfers (taxes) $T$ are nonzero except for the knife-edge case, where the negative pollution externality is exactly offset by the positive net capital externality, i.e., iff

$$
\eta=(1-\eta)(1-\alpha)
$$


In all other cases the following holds:

$$
T \gtrless 0 \quad \Longleftrightarrow \quad \eta \gtrless(1-\eta)(1-\alpha) .
$$

Although implementing optimal policy regimes leads to the welfare maximum, it is well observable that governments choose nonoptimal policy strategies for a number of reasons. Imperfect information about pollution damages or costs of abatement, as well as lobbying activities, only constitute some of the reasons behind these decisions. An interesting issue is therefore to consider the consequences of deviations from optimal policies for growth as well as labor supply. For this reason, we proceed in the following section with the analysis of the effects of changes in policies when policy instruments are not set at their optimal level.

\subsection{Comparative Statics for the Policy Instruments}

To compute the comparative statics of $l$ and $g$, we equate $\mu_{1}$ to $\mu_{2}$ from (38) and (39), and additionally consider $\tau^{p}=a A$, such that ${ }^{15}$

$$
\begin{aligned}
\beta & =\left\{1-\sigma^{2}(1-l)^{1-\alpha}\left[\left(\tau_{A}^{p}\right)^{\eta}-\tau_{A}^{p}\right]\right\} \\
& \times\left\{(1-l)^{1-\alpha}(1-\alpha)\left[\left(\tau_{A}^{p}\right)^{\eta}-\tau_{A}^{p}\right]\left(\frac{l^{\delta}}{1-l}-1\right)+\tau^{k}\right\} .
\end{aligned}
$$

As $\beta>0$ and $r_{s}>0$ for feasibility reasons, the second term on the RHS is positive in equilibrium. Employing the implicit function theorem, we can derive the following comparative static results for the policy instruments:

PROPOSITION 5. Equilibrium labor supply and growth increase in the neighborhood of the social optimum with a rise in the subsidy rate paid on capital accumulation. The effect of a change in the pollution tax, as measured by $\tau_{A}^{p}$, depends on whether the taxation exceeds or falls short of its optimal level. If the technological risk becomes too large, the response of equilibrium labor supply to an increase in the pollution tax may switch its sign:

(i)

$$
\begin{array}{ll}
\frac{\mathrm{d}(1-l)}{\mathrm{d} \tau^{k}}>0, & \\
\frac{\mathrm{d}(1-l)}{\mathrm{d} \tau_{A}^{p}} \gtreqless 0 & \text { for } \quad \tau_{A}^{p} \lesseqgtr \tau_{A}^{p *} \quad \text { if } \quad 1>2 \sigma^{2}(1-l)^{1-\alpha}\left[\left(\tau_{A}^{p}\right)^{\eta}-\tau_{A}^{p}\right], \\
\frac{\mathrm{d}(1-l)}{\mathrm{d} \tau_{A}^{p}} \lesseqgtr 0 & \text { for } \quad \tau_{A}^{p} \lesseqgtr \tau_{A}^{p *} \quad \text { if } \quad 1 \ll 2 \sigma^{2}(1-l)^{1-\alpha}\left[\left(\tau_{A}^{p}\right)^{\eta}-\tau_{A}^{p}\right] .
\end{array}
$$


(ii)

$$
\begin{aligned}
& \left.\frac{\mathrm{d} g}{\mathrm{~d} \tau^{k}}\right|_{\tau_{A}^{p *}, \tau^{k *}}>0, \\
& \left.\frac{\mathrm{d} g}{\mathrm{~d} \tau_{A}^{p}}\right|_{\tau_{A}^{p *}, \tau^{k *}} \gtreqless 0 \quad \text { for } \tau_{A}^{p} \lesseqgtr \tau_{A}^{p *} .
\end{aligned}
$$

Proof of Proposition 5. See Appendix D.

Proposition 5 states that-depending on the chosen policy-labor supply and growth can be higher or lower in the market economy than in the social optimum.

Changes in $\tau_{A}^{p}$. Whether labor supply is higher or lower than in the social optimum depends on whether or not the chosen policy overshoots or falls below its optimal value, i.e., $\tau_{A}^{p *} \gtreqless \tau_{A}^{p}$. Yet the direction in which labor supply responds to changes in $\tau_{A}^{p}$ depends on the volatility of the technology shock, $\sigma^{2}$. Given that the technological risk is relatively low, effects from the mean dominate effects from the stochastic component and the qualitative reaction of policy changes is the same as in a riskless economy. If, however, the technological risk is high, second-order effects can dominate. In this case the response of labor supply to a change in pollution is reversed.

Assume for the moment that $\sigma^{2}$ is low. In this case, the farther away from its optimal value the chosen tax rate is, the more labor supply falls short of its optimal level. If the tax rate is below its optimum, i.e., $\tau_{A}^{p}<\tau_{A}^{p *}$, abatement is suboptimally low, while pollution is too high. Consequently, the returns to labor fall short of the optimum and households substitute leisure for labor. The suboptimally low labor supply and the excess pollution both reduce growth. If, conversely, $\tau_{A}^{p}>\tau_{A}^{p *}$ holds, abatement activities exceed their optimal level and factor returns again are suboptimally low, such that labor supply as well as growth decrease. Changing the tax rate toward its optimal level will in both cases increase labor supply as well as growth (see Figure 1a).

Interestingly, the response of labor supply to a rise in the pollution tax might be reversed if the technological risk is sufficiently high (see Figure 1b). For $\tau_{A}^{p}<\tau_{A}^{p *}$, a rise in the tax rate raises net output as well as the volatility of production, which induces an increase in precautionary savings. In case this increase is sufficiently strong, the effect on the marginal return to labor is reversed and labor supply decreases. Still, with respect to growth the decrease in labor supply can never outweigh the positive effects of additional abatement, such that growth rises due to the increase in taxation.

Changes in $\tau^{k}$. Assume now that the incomplete internalization of the capital externality gives rise to distortions $\left(\tau^{k} \neq \tau^{k *}\right)$. In this case, the equilibrium labor 

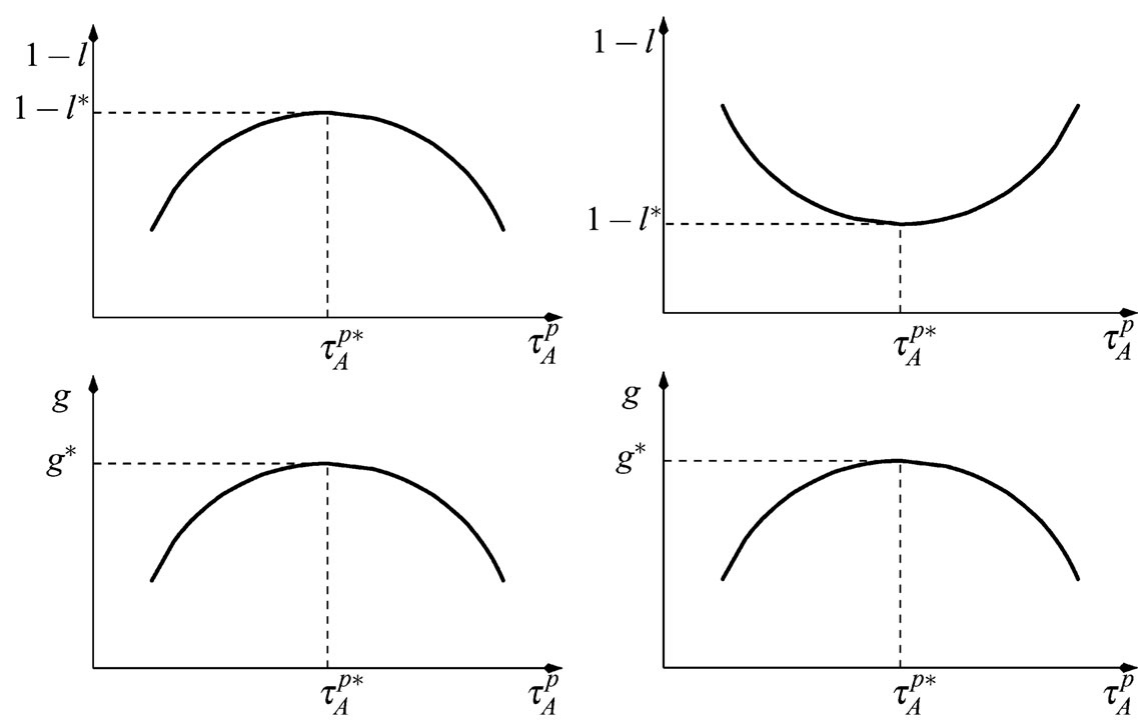

(a) Low-risk case

(b) High-risk case

FIGURE 1. Local behavior of growth rates and labor supply for a variation of $\tau_{A}^{p}$ around the social optimum.

supply in the market economy is below the optimal level, if $\tau^{k}$ is below its optimal level. For $\tau^{k}=\tau^{k *}$, labor supply becomes optimal, and for a further rise in the subsidy, labor supply rises to a suboptimally high level. The deviation of labor supply from its optimum level also determines whether the expected market growth rate exceeds or falls short of its optimum; i.e., $g \gtreqless g^{*}$ for $\tau^{k} \gtreqless \tau^{k *}$.

The intuition behind this result is that an increase in the subsidy on capital returns leads to an increase in capital formation and higher marginal factor returns. The increase in returns fosters growth in two ways: Higher returns to capital induce households to save more and lower their propensity to consume. Additionally, higher returns to labor induce households to substitute leisure for labor, which additionally enhances growth. Note that the effect on labor and growth is lower in the presence of technological risk. As the households' propensity to consume is always lower in the presence of risk (due to precautionary savings), an increase in the marginal return to capital decreases $\mu$ by less than under certainty; i.e., the "leverage effect" of an increase in the marginal return is lower.

\section{CONCLUSIONS}

This paper analyzes the effects of technological risk on long-run growth when labor supply is elastic and production gives rise to two types of externalities. On the one hand, production generates a flow of pollution that the individual producer takes as exogenous, which can be reduced by abatement activities. On the other 
hand, the input of capital induces a positive knowledge spillover. By considering additively separable preferences with respect to consumption and leisure, and by specifically assuming log-utility in consumption, growth effects of technology shocks can entirely be attributed to labor income risk.

Our analysis covers the socially optimal as well as the decentralized balanced growth path. We find that the optimal abatement ratio is constant along the balanced path and solely determined by the pollution elasticity of output. Whether an increase in the pollution elasticity affects labor supply positively or negatively crucially depends on the magnitude of risk, as measured by the variance of the technology shock. If production is deterministic, optimal labor supply and growth decrease due to an increase in the pollution sensitivity of production. If production is stochastic, second-order effects emerge and positively affect optimal labor supply. For a variance of the technology shock that is sufficiently high, these effects might prevail and give rise to an increase in labor supply.

We derive conditions for optimal policy design in the market economy, such that the decentralized allocation replicates the social optimum. The randomness of output requires optimal policy schemes to include a stochastic component in order to take account of the rising volatility of output. We assume the special case of deterministic and stochastic activities to be taxed/subsidized at uniform rates and leave the analysis of differentiated policy instruments for future research. A policy in the underlying setting is optimal if the tax on pollution and the subsidy on capital accumulation are set equal to their respective marginal externalities.

Furthermore, we examine more general properties of nonoptimal taxation and subsidy policies. We demonstrate that these properties can, but do not necessarily, coincide with the policy implications from nonstochastic models of pollution and growth. The inclusion of technology shocks might lead to a reversal of the responses of labor supply to changes in the policy variables. With respect to growth, however, stochastic effects never outweigh deterministic effects and the comparative statics of growth are of unambiguous sign.

Pollution in our model is assumed to be a flow variable, thereby allowing a straightforward integration of our setting into the existing literature on stochastic growth. Modeling pollution or resources as stock variables might, however, give rise to interesting additional insights. The consideration of risky stocks seems to be a promising field for future research, especially in the context of climate change.

\section{NOTES}

1. For a general overview of the role of uncertainty in environmental economics, see Pindyck (2006).

2. An extensive review of the related literature can be found in Pittel (2002).

3. Bars indicate aggregate values of variables.

4. We model pollution in our paper as a flow variable, as this somewhat reduces the complexity of the analytical analysis. However, Smulders and Gradus (1996) have shown in the context of deterministic growth models that the qualitative implications of a flow or stock formulation are equivalent as long as the focus is on balanced growth, which is the case in our paper.

5. In what follows, we drop the time index of variables for expository convenience. 
6. See Turnovsky and Smith (2006) for a solution procedure applying the stochastic Bellman equation.

7. $\mathrm{d} t \times \mathrm{d} t=0, \mathrm{~d} z_{i} \times \mathrm{d} z_{j}=\rho_{i j} \sigma_{i} \sigma_{j} \mathrm{~d} t$ for $i \neq j$, and $\mathrm{d} z_{i} \times \mathrm{d} z_{j}=\sigma^{2} \mathrm{~d} t$ for $i=j$.

8. In what follows, asterisks denote the Pareto-efficient values of the macroeconomic variables.

9. The safe asset is purely hypothetical, because we are dealing with an aggregate risk which cannot be diversified away.

10. This is not the case in the decentralized economy, as will become obvious below.

11. In the decentralized economy this would be equal to the risk-adjusted wage rate.

12. In an alternative approach, deterministic and stochastic flows could be treated at differentiated rates, but this is beyond the scope of the present paper [see, e.g., Clemens and Soretz $(1997,2004)]$. Also, we do not discuss state-dependent taxes and subsidies.

13. Recall that $r=r_{s}+$ risk premium.

14. A positive sign of $r_{s}$ is important for existence and uniqueness of the steady state. See also Clemens (2009) for an extensive discussion of the feasibility of balanced growth paths in continuoustime stochastic growth models with elastic labor supply.

15. As the comparative static results of variations in $\eta, \sigma^{2}$, and $\delta$ only get more complex without changing the qualitative results already derived above for the planner economy, we concentrate on the results for the policy instruments only.

\section{REFERENCES}

Ayong Le Kama, Alain and Katheline Schubert (2004) Growth, environment and uncertain preferences. Environmental and Resource Economics 28, 31-53.

Baranzini, Andrea and François Bourguignon (1995) Is sustainable growth optimal? International Tax and Public Finance 2, 341-356.

Beltratti, Andrea, Graciela Chichilnisky, and Geoffrey M. Heal (1998) Uncertain future preferences and conservation. In Graciela Chichilnisky and Alessandro Vercelli (eds.), Sustainability: Dynamics and Uncertainty, pp. 257-275. Dordrecht: Kluwer Academic.

Caballero, Ricardo J. (1990) Consumption puzzles and precautionary savings. Journal of Monetary Economics 25, 113-136.

Clemens, Christiane (2004) Status, risk-taking and intertemporal substitution in an endogenous growth model. Journal of Economics 83(2), 103-123.

Clemens, Christiane (2005) Income taxation, productive government expenditure and stochastic growth: On conditions for an optimal policy and the role of the risk premium. Topics in Macroeconomics 5(1), Article 14, BEPress.

Clemens, Christiane (2009) Stochastic growth and factor income risk. German Economic Review $10(4), 422-447$.

Clemens, Christiane and Susanne Soretz (1997) Macroeconomic effects of income taxation in a model of stochastic growth. Finanzarchiv, N. F. 54(4), 471-493.

Clemens, Christiane and Susanne Soretz (2004) Optimal fiscal policy, uncertainty and growth. Journal of Macroeconomics 26(4), 679-697.

Corsetti, Giancarlo (1997) A portfolio approach to endogenous growth: Equilibrium and optimal policy. Journal of Economic Dynamics and Control 21, 1627-1644.

Domar, Evsey D. and Richard A. Musgrave (1944) Proportional income taxation and risk-taking. Quarterly Journal of Economics 59, 388-422.

Eaton, Jonathan (1981) Fiscal policy, inflation and the accumulation of risky capital. Review of Economic Studies 48, 435-445.

Gradus, Raymond and Sjak A. Smulders (1993) The trade-off between environmental care and longterm growth: Pollution in three prototype growth models. Journal of Economics 58(1), 25-51.

Grimaud, Andre (1999) Pollution permits and sustainable growth in a Schumpeterian model. Journal of Environmental Economics and Management 38(3), 249-266. 
Grimaud, Andre and Luc Rougé (2005) Polluting non-renewable resources, innovation and growth: Welfare and environmental policy. Resource and Energy Economics 27, 109-129.

Groth, Christian and Poul Schou (2007) Growth and non-renewable resources: The different roles of capital and resource taxes. Journal of Environmental Economics and Management 53, 80-98.

Hubbard, R. Glenn, Jonathan Skinner, and Stephen P. Zeldes (1994) The importance of precautionary motives in explaining individual and aggregate saving. Carnegie-Rochester Conference Series on Public Policy 40, 59-126.

Intergovernmental Panel on Climate Change. [IPCC] (2007) Climate Change 2007: Impacts, Adaptation and Vulnerability. Summary for Policy-Makers. IPCC.

King, Robert G. and Sergio T. Rebelo (1999) Resuscitating real business cycles. In John B. Taylor and Michael Woodford (eds.), Handbook of Macroeconomics, vol. Ib, pp. 927-1007. Amsterdam: North-Holland.

Leland, Hayne E. (1968) Saving and uncertainty: The precautionary demand for saving. Quarterly Journal of Economics 82, 465-473.

Levhari, D. and T. N. Srinivasan (1969) Optimal savings under uncertainty. Review of Economic Studies 36, 153-163.

Malliaris, Anastasios G. and William A. Brock (1982) Stochastic Methods in Economics and Finance. Amsterdam: North-Holland.

Merton, Robert C. (1982) On the microeconomic theory of investment under uncertainty. In Kenneth J. Arrow and Michael D. Intriligator (eds.), Handbook of Mathematical Economics, vol. II, pp. 601669. Amsterdam: North-Holland.

Obstfeld, Maurice (1994) Risk-taking, global diversification, and growth. American Economic Review 84, 1310-1329.

Pindyck, Robert S. (2002) Optimal timing problems in environmental economics. Journal of Economic Dynamics and Control 26, 1677-1697.

Pindyck, Robert S. (2006) Uncertainty in Environmental Economics. NBER working paper 12752, National Bureau of Economic Research, Cambridge, MA.

Pittel, Karen (2002) Sustainability and Endogenous Growth. Cheltenham, UK: Edward Elgar.

Romer, Paul M. (1986) Increasing returns and long-run growth. Journal of Political Economy 94, 1002-1037.

Sandmo, Agnar (1970) The effect of uncertainty on savings decisions. Review of Economic Studies $37,353-360$.

Schou, Poul (2000) Polluting non-renewable resources and growth. Environmental and Resource Economics 16(2), 211-227.

Schou, Poul (2002) When environmental policy is superfluous: Growth and polluting resources. Scandinavian Journal of Economics 104, 605-620.

Smith, William T. (1996) Taxes, uncertainty, and long-term growth. European Economic Review 40(8), 1647-1664.

Smulders, Sjak A. and Raymond Gradus (1996) Pollution abatement and long-term growth. European Journal of Political Economy 12, 505-532.

Soretz, Susanne (2003) Stochastic pollution and environmental care in an endogenous growth model. Manchester School 71(4), 448-469.

Soretz, Susanne (2004) Stochastic environmental policy, risk-taking, and growth: Discretion versus commitment. International Journal of Global Environmental Issues 4, 58-72.

Soretz, Susanne (2007) Efficient dynamic pollution taxation in an uncertain environment. Environmental and Resource Economics 36(1), 57-84.

Stern, Nicholas (2006) The Economics of Climate Change-The Stern Review. Cambridge, UK: Cambridge University Press.

Stiglitz, Joseph E. (1969) The effects of income, wealth, and capital-gains taxation on risktaking. Quarterly Journal of Economics 83, 263-283.

Turnovsky, Stephen J. (1993) Macroeconomic policies, growth, and welfare in a stochastic economy. International Economic Review 34, 953-981. 
Turnovsky, Stephen J. (2000) Fiscal policy in a stochastically growing economy with elastic labor supply. Journal of Public Economic Theory 2, 389-433.

Turnovsky, Stephen J. (2003) On the introduction of endogenous labour income in deterministic and stochastic growth models. In Sumru Altug, Jagijt S. Chadha, and Charles Nolan (eds.), Dynamic Macroeconomic Analysis. Theory and Policy in General Equilibrium, pp. 487-508. Cambridge, UK: Cambridge University Press.

Turnovsky, Stephen J. and William T. Smith (2006) Equilibrium consumption and precautionary saving in a stochastically growing economy. Journal of Economic Dynamics and Control 30, 243-278.

Zeldes, Stephen P. (1989) Optimal consumption with stochastic income: Deviations from certainty equivalence. Quarterly Journal of Economics 104, 275-298.

\section{APPENDIX}

\section{A.1. PROOF OF PROPOSITION 3}

The comparative statics of labor supply can be obtained by employing the implicit function theorem to (23) to yield

$$
\begin{aligned}
& \frac{\mathrm{d}(1-l)^{*}}{\mathrm{~d} \sigma^{2}}=-\frac{l^{\delta}}{\beta B} \frac{1-\alpha}{(1-l)^{2 \alpha-1}} Z^{2}<0 \\
& \frac{\mathrm{d}(1-l)^{*}}{\mathrm{~d} \delta}=\frac{\ln l}{B}<0 \\
& \frac{\mathrm{d}(1-l)^{*}}{\mathrm{~d} \eta}=\frac{l^{\delta}}{\beta B} \frac{1-\alpha}{(1-l)^{\alpha}}\left[1-2 \sigma^{2}(1-l)^{1-\alpha} Z\right] \frac{\mathrm{d} Z}{\mathrm{~d} \eta} \lesseqgtr 0 \quad \text { for } 1 \gtreqless 2 \sigma^{2}(1-l)^{1-\alpha} Z,
\end{aligned}
$$

with $Z=(1-\eta) \eta^{\eta /(1-\eta)}$ and

$$
B=\frac{\delta}{l}+\frac{\alpha}{1-l}+\frac{\sigma^{2} Z \frac{1-\alpha}{(1-l)^{\alpha}}}{1-\sigma^{2} Z \frac{1-\alpha}{(1-l)^{\alpha}}}>0 \quad \text { and } \quad \frac{\mathrm{d} Z}{\mathrm{~d} \eta}=\frac{Z}{(1-\eta)^{2}} \ln \eta<0
$$

The comparative statics of the growth rate follow from differentiation of (24) with respect to the model parameters, taking into account the response of $1-l$ to changes in the parameters:

$$
\begin{aligned}
& \frac{\mathrm{d} g^{*}}{\mathrm{~d} \sigma^{2}}=-\left(g^{*}+\beta\right) \frac{1-\alpha}{1-l} \frac{\mathrm{d} l}{\mathrm{~d} \sigma^{2}}<0, \\
& \frac{\mathrm{d} g^{*}}{\mathrm{~d} \delta}=-\left(g^{*}+\beta\right) \frac{1-\alpha}{1-l} \frac{\mathrm{d} l}{\mathrm{~d} \delta}<0, \\
& \frac{\mathrm{d} g^{*}}{\mathrm{~d} \eta}=-\frac{\mathrm{d} Z}{\mathrm{~d} \eta} \frac{(1-l)^{1-\alpha}\left(1-\sigma^{2}(1-l)^{1-\alpha} Z\right)\left(\frac{\delta}{l}+\frac{\alpha}{1-l}\right)}{\left(1-\sigma^{2}(1-l)^{1-\alpha} Z\right)\left(\frac{\delta}{l}+\frac{1}{1-l}\right)+\frac{1-\alpha}{1-l} \sigma^{2}(1-l)^{1-\alpha} Z}<0 .
\end{aligned}
$$




\section{A.2. OPTIMIZATION IN THE DECENTRALIZED ECONOMY}

The budget constraint of the representative household is

$$
\begin{aligned}
\mathrm{d} K & =\left(K^{\alpha}[\bar{K}(1-l)]^{1-\alpha} \bar{P}^{-\eta}-C-A+T-\tau^{p}\left\{\frac{K^{\alpha}[\bar{K}(1-l)]^{1-\alpha}}{A}\right\}+\tau^{k} K\right) \mathrm{d} t \\
& +\left(K^{\alpha}[\bar{K}(1-l)]^{1-\alpha} \bar{P}^{-\eta}-A+T-\tau^{p}\left\{\frac{K^{\alpha}[\bar{K}(1-l)]^{1-\alpha}}{A}\right\}+\tau^{k} K\right) \mathrm{d} z .
\end{aligned}
$$

The stochastic Hamiltonian can be set up as follows:

$$
\begin{aligned}
& H\left(C, K, A, l, \lambda, \frac{\partial \lambda}{\partial K}\right)=e^{-\beta t}\left(\ln C+\frac{l^{1-\delta}}{1-\delta}\right)+\lambda\left(K^{\alpha} \bar{K}^{1-\alpha}(1-l)^{1-\alpha} \bar{P}^{-\eta}-C\right. \\
& \left.-A+T-\tau^{p}\left\{\frac{K^{\alpha}[\bar{K}(1-l)]^{1-\alpha}}{A}\right\}+\tau^{k} K\right)+\frac{\sigma_{K}^{2}}{2} \frac{\partial \lambda}{\partial K},
\end{aligned}
$$

where aggregate pollution is exogenous, and

$$
\sigma_{K}^{2}=\left(K^{\alpha}[\bar{K}(1-l)]^{1-\alpha} a^{\eta}-A+T-\tau^{p}\left\{\frac{K^{\alpha}[\bar{K}(1-l)]^{1-\alpha}}{A}\right\}+\tau^{k} K\right)^{2} \sigma^{2}
$$

Maximization leads to the following FOCs, where we have already taken account of $P=1 / a$ and the government budget constraint (35):

$$
\begin{aligned}
\frac{\partial H}{\partial C}= & e^{-\beta t} C^{-1}-\lambda=0 \\
\frac{\partial H}{\partial l}= & e^{-\beta t} l^{-\delta}-\lambda K \frac{1-\alpha}{1-l}\left[a^{\eta}(1-l)^{1-\alpha}-\frac{\tau^{p}}{a K}\right]\left[1+\sigma^{2} \frac{\partial \lambda}{\partial K} \frac{K}{\lambda}(1-l)^{1-\alpha}\left(a^{\eta}-a\right)\right] \\
= & 0, \\
\frac{\partial H}{\partial A}= & \left(\tau^{p} \frac{1}{a A}-1\right)\left[1+\sigma^{2} \frac{\partial \lambda}{\partial K} \frac{K}{\lambda}(1-l)^{1-\alpha}\left(a^{\eta}-a\right)\right]=0 \\
\mathrm{~d} \lambda= & -\frac{\partial H}{\partial K} \mathrm{~d} t+\frac{\partial \lambda}{\partial K} \sigma_{K} \mathrm{~d} z \\
= & -\lambda\left(\left[\alpha a^{\eta}(1-l)^{1-\alpha}+\tau^{k}-\alpha \frac{\tau^{p}}{a K}\right]\left\{1+\sigma^{2} \frac{\partial \lambda}{\partial K} \frac{K}{\lambda}\left[(1-l)^{1-\alpha}\left(a^{\eta}-a\right)\right]\right\} \mathrm{d} t\right. \\
& \left.+\frac{\partial \lambda}{\partial K} \frac{K}{\lambda}\left[(1-l)^{1-\alpha}\left(a^{\eta}-a\right)\right] \mathrm{d} z\right) .
\end{aligned}
$$

The first-order conditions (A.9) and (A.10) with respect to consumption and leisure are identical in structure compared to the associated conditions of the planner problem. The 
pollution tax is tied to individually generated pollution. The representative agent knows that he or she can avoid/reduce tax payments by voluntarily undertaking abatement efforts, which is reflected in condition (A.11).

\section{A.3. EXISTENCE OF THE GROWTH EQUILIBRIUM IN THE MARKET ECONOMY}

A unique balanced growth path exists for the decentralized economy if

(i) the certainty equivalent to capital return is positive;

(ii) $\Delta$ is a continuous and monotonically increasing function in the domain $l \in(0,1)$;

(iii) the limits of $\Delta$ are of opposite sign:

$$
\operatorname{sgn} \lim _{(1-l) \rightarrow 0} \Delta=-\operatorname{sgn} \lim _{(1-l) \rightarrow 1} \Delta .
$$

Differentiation of (43) with respect to $1-l$ gives

$$
\begin{aligned}
& \frac{\partial \Delta}{\partial(1-l)}=-(1-\alpha)(1-l)^{-\alpha}\left[\left(\tau_{A}^{p}\right)^{\eta}-\tau_{A}^{p}\right] \\
& \quad \times\left[\left\{1-\sigma^{2}(1-l)^{1-\alpha}\left[\left(\tau_{A}^{p}\right)^{\eta}-\tau_{A}^{p}\right]\right\}\left[1-\alpha+l^{\delta}\left(\frac{\delta}{l}+\frac{\alpha}{1-l}\right)\right]\right. \\
& \left.\quad+(1-\alpha)\left(1+\sigma^{2}\left\{\left[\left(\tau_{A}^{p}\right)^{\eta}-\tau_{A}^{p}\right]\left(\frac{l^{\delta}}{1-l}-1\right)+\tau^{k}\right\}\right)\right],
\end{aligned}
$$

which is negative for $r_{s}>0$. As can be seen from (39) and (41), a positive certainty equivalent to capital return is required for growth and consumption to be feasible. The second row of (A.12) is positive given (45).

The limits of $\Delta$ with respect to $(1-l) \rightarrow 0$ and $(1-l) \rightarrow 1$ are given by

$$
\lim _{(1-l) \rightarrow 1} \Delta=-\beta-\left\{1-\sigma^{2}\left[\left(\tau_{A}^{p}\right)^{\eta}-\tau_{A}^{p}\right]\right\}(1-\alpha)\left[\left(\tau_{A}^{p}\right)^{\eta}-\tau_{A}^{p}\right]<0 \text { and } \lim _{(1-l) \rightarrow 0} \Delta=\infty .
$$

\section{A.4. PROOF OF PROPOSITION 5}

The comparative statics of labor supply with respect to the two policy instruments can be derived by employing the implicit function theorem to (45), to yield

$$
\begin{aligned}
& \frac{\mathrm{d}(1-l)}{\mathrm{d} \tau^{k}}=\frac{D}{F}>0, \\
& \frac{\mathrm{d}(1-l)}{\mathrm{d} \tau_{A}^{p}}=\frac{E}{F} \gtreqless 0 \quad \text { for } \quad \tau_{A}^{p} \lesseqgtr \tau_{A}^{p *},
\end{aligned}
$$


with

$$
\begin{aligned}
D= & {\left[1-\sigma^{2}(1-l)^{1-\alpha} G\right]>0, } \\
E=- & \frac{\mathrm{d} G}{\mathrm{~d} \tau_{A}^{p}}(1-l)^{1-\alpha}\left[(1-\alpha)\left[1-2 \sigma^{2}(1-l)^{1-\alpha} G\right]\left(\frac{l^{\delta}}{1-l}-1\right)+\sigma^{2} \tau^{k}\right] \gtreqless 0 \\
& \quad \text { for } \tau_{A}^{p *} \lesseqgtr \tau_{A}^{p}, \\
F= & (1-\alpha)(1-l)^{-\alpha} G\left\{\left[1-\sigma^{2}(1-l)^{1-\alpha} G\right]\left[(1-\alpha)+l^{\delta}\left(\frac{\delta}{l}+\frac{\alpha}{1-l}\right)\right]\right. \\
& \left.+\sigma^{2}\left[(1-\alpha)(1-l)^{1-\alpha} G\left(\frac{l^{\delta}}{1-l}-1\right)+\tau^{k}\right]\right\}>0,
\end{aligned}
$$

where $G=\left(\tau_{A}^{p}\right)^{\eta}-\tau_{A}^{p}$ and therefore

$$
\frac{\mathrm{d} G}{\mathrm{~d} \tau_{A}^{p}}=\eta\left(\tau_{A}^{p}\right)^{\eta-1}-1 \gtreqless 0 \quad \text { for } \quad \tau_{A}^{p} \lesseqgtr \tau_{A}^{p *} .
$$

From (45), it follows that $(1-\alpha) l^{\delta}(1-l)^{-\alpha} G\left(\frac{l^{\delta}}{1-l}-1\right)+\tau^{k}>0$. The sign of $E$ depends on $1-2 \sigma^{2}(1-l)^{1-\alpha} G$. A sufficient condition for $E$ to be positive [as postulated in (A.13) and (A.14)] is $1>2 \sigma^{2}(1-l)^{1-\alpha} G$. In case this condition does not hold, i.e., if the second-order part dominates the first-order one, the sign of $E$ may switch.

The comparative statics of the growth rate can be obtained from differentiating (41) with respect to the respective parameters and labor supply while considering the change of $1-l$ with respect to the tax and subsidy rates:

$$
\begin{aligned}
\left.\frac{\mathrm{d} g}{\mathrm{~d} \tau_{A}^{p}}\right|_{\tau_{A}^{p *}, \tau^{k *}}= & \frac{\mathrm{d} G}{\mathrm{~d} \tau_{A}^{p}} \frac{(1-\alpha)(1-l)^{1-2 \alpha} G}{F}\left[\alpha+\sigma^{2}(1-\alpha)(1-l)^{1-\alpha} \frac{a(1-\eta)}{\eta}\right] \\
\times & \left\{\left[1-\sigma^{2}(1-l)^{1-\alpha} G\right] l^{\delta}\left(\frac{\delta}{l}+\frac{1}{1-l}\right)\right\} \gtreqless 0 \text { for } \tau_{A}^{p} \lesseqgtr \tau_{A}^{p *}, \\
\left.\frac{\mathrm{d} g}{\mathrm{~d} \tau^{k}}\right|_{\tau_{A}^{p *}, \tau^{k *}}= & {\left[\alpha+\sigma^{2}(1-\alpha)(1-l)^{1-\alpha} \frac{a(1-\eta)}{\eta}\right]\left[\frac{\mathrm{d}(1-l)}{\mathrm{d} \tau^{k}} \frac{1-\alpha}{(1-l)^{\alpha}} G\right] } \\
& +\left[1-\sigma^{2}(1-l)^{1-\alpha} G\right]>0 .
\end{aligned}
$$

